Check for updates

Cite this: RSC Adv., 2018, 8, 41624

Received 29th September 2018 Accepted 3rd December 2018

DOI: $10.1039 / \mathrm{c} 8 \mathrm{ra08093c}$

rsc.li/rsc-advances

\section{Uptake and release of photosensitizers in a hydrogel for applications in photodynamic therapy: the impact of structural parameters on intrapolymer transport dynamics $\uparrow$}

\begin{abstract}
Sarah Glass, Tom Rüdiger, Jan Griebel, Bernd Abel (D) and Agnes Schulze (DD *
In this study a hydrogel is presented that can be used as a carrier and release system for photosensitizers. Because of the high structural variety of photosensitizers, four different substances were analysed. Two porphyrins, 5,10,15,20-tetrakis(1-methyl-4-pyridinio)porphyrin tetra( $p$-toluene-sulfonate) and sodium

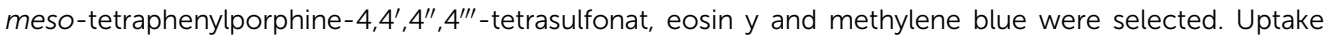
and release of these photosensitizers were studied. All photosensitizers were taken up by the hydrogel not depending significantly on the structure of the photosensitizer, and it was possible to load the hydrogels in the $\mu \mathrm{mol} \mathrm{g}{ }^{-1}$ range. Nevertheless, size and $\mathrm{p} K_{\mathrm{a}}$ value were shown to influence the release behaviour. Finally, the singlet oxygen generation of the photosensitizer after release was demonstrated. The photosensitizer was still highly active and produced a sufficient amount of singlet oxygen.
\end{abstract}

\section{Introduction}

Photodynamic therapy (PDT) is a promising medical therapy, e.g. for cancer treatment. ${ }^{1}$ In PDT so called photosensitizers are used. Photosensitizers were investigated by Oscar Raab at the beginning of the last century. ${ }^{2} \mathrm{He}$ observed that these compounds can treat cells when irradiated with light. In the 1930's the mechanism of the phenomenon was observed. Kautsky et al. ${ }^{47}$ found out that singlet oxygen or other reactive oxygen species (ROS) are formed due to the reaction of the excited photosensitizer with oxygen from the air or cell metabolism.

In the 1950's hematoporphyrin (a powerful photosensitizer) was found to be tumour localizing and accumulates in cancerous tissue. ${ }^{3}$ This unique combination offered the possibility to treat cancer by using a photosensitizer and light. Starting with this, the field of PDT became more and more important and in 1999 the first photosensitizer was approved. ${ }^{1}$ Since then, lots of further second and third generation photosensitizers have been developed that treat not only cancer but microorganisms (e.g., bacteria, fungi, viruses), too. ${ }^{4}$ Additionally, inorganic photosensitizers like $\mathrm{TiO}_{2}$ and $\mathrm{ZnO}$ have been investigated in the last years. ${ }^{5,6}$

A well-known type of second generation photosensitizer is porphyrins, $^{7} \quad$ like $\quad 5,10,15,20$-tetrakis(1-methyl-4-pyridinio) porphyrin tetra( $p$-toluene-sulfonate) (TMPyP) and sodium

Leibniz Institute of Surface Engineering (IOM), Germany. E-mail: agnes.schulze@ iom-leipzig. de

$\dagger$ Electronic supplementary information (ESI) available. See DOI: $10.1039 / \mathrm{c} 8 \mathrm{ra} 08093 \mathrm{c}$ meso-tetraphenylporphine- $4,4^{\prime}, 4^{\prime \prime}, 4^{\prime \prime \prime}$-tetrasulfonat $\quad\left(\mathrm{TPPS}_{4}\right)$. Porphyrins are known to be highly efficient. They generate a high amount of reactive species (especially singlet oxygen) ${ }^{8-10}$ and have high absorption coefficients. Therefore, they are widely used in cancer therapy, ${ }^{11}$ dentistry ${ }^{12}$ and as treatment for bacteria. ${ }^{13}$ Furthermore xanthene dyes are important photosensitizers. ${ }^{14}$ Eosin y, a typical xanthene photosensitizer, is reported to be highly effective in treating Gram-positive and Gram-negative bacteria. ${ }^{15,16}$ The last family of substances mentioned here are phenothiazine dyes. The most prominent representative is methylene blue. ${ }^{17}$ It is a widely used drug (not only in photomedicine), e.g. in dentistry or antimicrobial applications..$^{18}$ Methylene blue is known to generate a high amount of singlet oxygen and ROS. ${ }^{17}$ Furthermore, it is known that methylene blue is effective against bacteria while it is not damaging white blood cells. ${ }^{19}$

Today, PDT is a widely used therapy not only against cancer. Additionally, photosensitizers are used in dentistry ${ }^{12}$ and in wound treatment. ${ }^{20}$ As well as cancer cells, microorganisms like bacteria or fungi can also be attacked by photosensitizers. ${ }^{1}$

Therefore, nowadays challenges (e.g. wound healing) can be faced by using PDT. It was already demonstrated that photosensitizers can improve wound healing in acute wounds as well as in chronic ones. ${ }^{21}$ One challenge in using PDT for wound management is the lack of a comfortable carrier system that releases compounds and that is transparent for activating light. One possibility is the use of hydrogels that are already wellknown in wound therapy..$^{22,23}$

Generally, there are further carrier systems. Especially, nanoparticle-based systems have been discussed in the past. ${ }^{5,24}$ 
Nevertheless, hydrogels can be used as bandage material and drug delivery system simultaneously. ${ }^{25,26}$

Hydrogels are three-dimensional polymeric networks synthesised of highly hydrophilic monomers. ${ }^{27}$ There is a great variety of monomers used in hydrogel synthesis, such as polyamides, ${ }^{28}$ poly (ethylene oxide), ${ }^{29}$ polyacryl acid derivates, ${ }^{30-32}$ gelatin $^{33}$ and many more. Features vary with monomer structure and chain length. The number of applications is as high as the number of monomers. Typical fields of application are cell immobilization, ${ }^{34}$ tissue engineering, ${ }^{35}$ wound care ${ }^{22}$ and drug delivery. ${ }^{36}$

Hydrogels can protect wounds and keep them moist, which is beneficial in wound management. ${ }^{37}$ At the same time they can be used as a carrier system for drugs like photosensitizers. In this case the hydrogel has to be transparent to ensure the excitation of the photosensitizer by light. Therefore, the bandage would not have to be changed. This prevents the patient from additional pain.

In a recent study a transparent, noncytotoxic, low-molecular weight and inexpensive hydrogel was introduced and optimized. ${ }^{6,38}$ The present study investigates this hydrogel as a transparent carrier system for molecular photosensitizers. For this purpose, a high variety of different photosensitizers was evaluated regarding adsorption and release dynamics. The photosensitizers were selected regarding their different structures, sizes and charges. Additionally, the photosensitizer activity (generation of singlet oxygen) was investigated to demonstrate the suitability of the hydrogel system in PDT.

\section{Experimental}

\subsection{Materials}

Poly(ethylene glycol)diacrylate (PEGDA), eosin y, 5,10,15,20tetrakis(1-methyl-4-pyridinio)porphyrin tetra( $p$-toluene-sulfonate) (TMPyP), sodium meso-tetraphenylporphine- $4,4^{\prime}, 4^{\prime \prime}, 4^{\prime \prime \prime}$-tetrasulfonat $\left(\mathrm{TPPS}_{4}\right)$, methylene blue, 9,10-anthracenediyl-bis(methylene) dimalonic acid (ABDA) and phosphate buffered saline (PBS) were purchased from Sigma Aldrich (St. Louise, USA).

The photoinitiator 1-[4-(2-hydroxyethoxy)-phenyl]-2-hydroxy2-methyl-1-propane-1-one ( $\alpha$-HAP) was purchased from IGM Resins B.V. (Waalwijk, the Netherlands). A Merck ultrapure water system was used to purify water. All chemicals were used without further purification.

\subsection{Preparation of the hydrogels}

The hydrogels were prepared like described before. ${ }^{38}$ A formulation of $30 \mathrm{wt} \%$ PEGDA, PBS and the commercial photoinitiator $\alpha$-HAP was prepared. $1 \mathrm{ml}$ of the formulation was injected in a polystyrene mould with a diameter of $3.5 \mathrm{~cm}$. This corresponds to a height of $1 \mathrm{~mm}$. The moulds were irradiated with a medium-pressure mercury lamp. The light dose was 2500

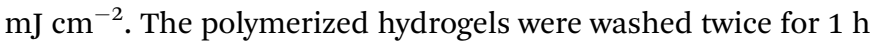
in PBS buffer and three times for $1 \mathrm{~h}$ in Milli-Q water. Afterwards, they were dried for $24 \mathrm{~h}$ at $40{ }^{\circ} \mathrm{C}$ in a nitrogen atmosphere.

\subsection{UV/VIS spectra and determination of the extinction coefficients}

UV/VIS spectra were recorded with an UV-2101PC UV-VIS spectrometer (Shimadzu, Kyoto, Japan) using Milli-Q water as solvent. Extinction coefficients were calculated at the maximum absorption wavelength using Beer-Lambert-law. ${ }^{39}$

$$
E_{\lambda}=\lg \frac{I_{0}}{I}=-\lg T=\varepsilon_{\lambda} c d
$$

$E_{\lambda}$ is defined as extinction at the wavelength $\lambda . I_{0}$ is the initial intensity of the light, while $I$ is the intensity of light after passing the sample. $\varepsilon_{\lambda}$ is the molar extinction coefficient, which depends on the wavelength and the sample. $d$ is the diameter of the cuvette. In this case $d$ was $1 \mathrm{~cm}$. $T$ is the transmittance of the hydrogels. The concentrations $c$ of the different samples are listed in Table 1.

\subsection{Uptake studies}

To determine the relative amount of the photosensitizers the hydrogels were immersed in solutions of various concentrations for 24,48 and $120 \mathrm{~h}$. The loaded gels were dried for $24 \mathrm{~h}$ at $40{ }^{\circ} \mathrm{C}$ in a nitrogen atmosphere. The transmittance $(T)$ of the dried gels was determined with an UV-2101PC UV-VIS spectrometer.

The dry loaded gels were completely dissolved in $10 \mathrm{ml} 2 \mathrm{~N}$ $\mathrm{NaOH}$ per gel for $120 \mathrm{~h}$. The concentration of dye in this solution was determined photometrically using an infinite M200 reader from Tecan (Maennedorf, Switzerland). As reference, a defined concentration $\left(1.0 \times 10^{-3} \mathrm{~mol} \mathrm{l}^{-1}\right.$ for methylene blue and eosin y, and $1.0 \times 10^{-4} \mathrm{~mol} \mathrm{l}^{-1}$ for TMPyP and $\mathrm{TPPS}_{4}$, respectively) of each dye in $2 \mathrm{~N} \mathrm{NaOH}$ was used.

From these concentrations the absolute amount of substance $(n)$ was calculated. The theoretical amounts were calculated using:

$$
n=c V
$$

where $V$ is the volume of the swollen gel $(1 \mathrm{ml})$ and $c$ is the concentration of the solution.

The relative uptake of the hydrogels was calculated for the lowest concentration of each photosensitizer. Extinction coefficients were determined using the calculated absolute amounts of photosensitizer and the transmittance of the hydrogels. Eqn (1) was used. The amount of the photosensitizer was calculated from the transmittance spectra at different times using the extinction coefficient. The relative amount of photosensitizer in the gels was calculated at all observed times and compared with

Table 1 Concentrations of photosensitizers for the determination of the extinction coefficient

Concentration $c$ $\left[\mathrm{mol} \mathrm{l}^{-1}\right.$ ]

Methylene blue

Eosin y

TMPyP

$\mathrm{TPPS}_{4}$
$1.1 \times 10^{-5}$

$1.0 \times 10^{-5}$

$2.7 \times 10^{-6}$

$2.4 \times 10^{-6}$ 
the theoretical amount. The extinction coefficients of the photosensitizers in hydrogels differ slightly from the extinction coefficients in water and therefore, they had to be determined, additionally.

\subsection{Rheology}

Rheology was performed before and after loading of the hydrogel. The hydrogels were immersed in $10 \mathrm{ml} 1 \times 10^{-4} \mathrm{M}$ solution of the respective photosensitizer for $48 \mathrm{~h}$. Rheological measurements of the dried hydrogels were performed on a MCR300 rheometer from Anton Paar (Graz, Austria). The rheometer was equipped with a planar $25 \mathrm{~mm}$ diameter head. The frequency was varied from 0.16 to $16 \mathrm{~Hz}$. The probe head was pressed on the sample with a pressure of $10 \mathrm{~N}$. The amplitude was $1 \%$.

The mesh sizes of the hydrogels were calculated from the rheological data using: ${ }^{\mathbf{4 0 , 4 1}}$

$$
\xi=\left(\frac{G^{\prime}}{R T}\right)^{-\frac{1}{3}}
$$

wherein $\xi$ is the mesh size, $G^{\prime}$ is the storage modulus, $R$ is the universal gas constant and $T$ is the temperature.

\subsection{Atomic force microscopy (AFM)}

AFM investigations were carried out on a Nanowizard IV (JPK Instruments, Berlin, Germany) scanning probe microscope using silicon cantilevers (PPP-NCHR, nanosensors ${ }^{\mathrm{TM}}$ ) with tip radii of about $7 \mathrm{~nm}$. The phase and height images were obtained by operating the instrument in intermittent contact mode in ambient condition.

In preparation of AFM thin sections $(\sim 150 \mathrm{~nm})$ of the hydrogel were cut with a cryo-ultramicrotome (PT-CRX LN Ultra with CR-X cryo unit, RMC, USA) at cryo temperature of $-60{ }^{\circ} \mathrm{C}$ using diamond knives.

\subsection{Release studies}

The hydrogel was dried after loading with the photosensitizer. Afterwards, it was immersed in $10 \mathrm{ml}$ PBS buffer to release the dye from the hydrogels. The PBS buffer was changed after 1, 2, $3,4,5,6,8,24,48$ and $72 \mathrm{~h}$. The concentrations, and therefore, the amounts of substance of the samples were determined photometrically with an infinite M200 reader from Tecan.

\subsection{Singlet oxygen generation}

The generation of singlet oxygen was determined using the fluorescent dye ABDA. This dye reacts selectively with singlet oxygen to a nonfluorescent product. Before usage pure $\mathrm{O}_{2}$ was bubbled through the ABDA solution to ensure comparable oxygen saturation with every measurement. $6 \mathrm{ml}$ of a $5 \times$ $10^{-4} \mathrm{M}$ ABDA solution were applied to a wet hydrogel immersed in $1 \times 10^{-4} \mathrm{M}$ methylene blue solution. This was irradiated with a $940 \mathrm{~mW}$ LED (Thorlabs, Newton, USA) emitting at $660 \mathrm{~nm}$. The LED was placed $10 \mathrm{~cm}$ above the sample (corresponds to 1.1 $\mathrm{mW} \mathrm{cm}^{-2}$ ). Samples were taken every $15 \mathrm{~min}$ within the first hour and then every $30 \mathrm{~min}$. The volume of the sample $(100 \mu \mathrm{l})$ was replaced with water. The fluorescence of ABDA at $422 \mathrm{~nm}$ was observed photometrically with an infinite M200 reader from Tecan (Maennedorf, Switzerland). As reference, a pure hydrogel in ADBA solution was investigated.

\subsection{Photosensitizer size (Stokes-radius)}

To determine the Stokes radius of the photosensitizers, DOSY (Diffusion Ordered Spectroscopy) NMR spectra using watergate sequence for solvent suppression were recorded. Herein, a Bruker NMR Ultra Shield $600 \mathrm{MHz}$ was used. 4,4-Dimethyl-4silapentane-1-sulfonic acid (DSS) was used as internal NMR standard. Stokes radii were calculated from the received diffusion coefficients $D$ using the Stokes-Einstein-equation:

$$
R_{\mathrm{H}}=\frac{k_{\mathrm{B}} T}{6 \pi D \eta}
$$

wherein $R_{\mathrm{H}}$ is the Stokes radius, $k_{\mathrm{B}}$ is the Boltzmann constant $\left(1.38 \times 10^{-23} \mathrm{~J} \mathrm{~K}^{-1}\right) . T$ is the temperature during the measurement, which was $293 \mathrm{~K}$. The viscosity of the solvent $\mathrm{D}_{2} \mathrm{O} \eta$ was $1.25 \mathrm{cP}^{42}$

\subsection{Determination of $\mathrm{pK}_{\mathrm{a} ; 1}$}

The $\mathrm{p} K_{\mathrm{a}}$ values were determined using acid-base titration. The photosensitizers were dissolved in Milli-Q water. The solution was divided equally. Afterwards, one part was titrated using $0.1 \mathrm{M} \mathrm{NaOH}$ solution. The other part was titrated using $0.1 \mathrm{M}$ $\mathrm{HCl}$. The $\mathrm{pH}$ values were recorded using a HI $3220 \mathrm{pH} / \mathrm{ORP}$ meter (HANNA instruments, Woonsocket, USA). Eosin y, TMPyP and $\mathrm{TPPS}_{4}$ are polyprotic acids. Here, the lowest $\mathrm{p} K_{\mathrm{a}}$ value is displayed.

\section{Results and discussion}

\subsection{Material properties}

First, the material was analysed regarding its mechanical properties. Thus, rheology was used to determine moduli and loss factor. The storage and dynamic moduli were $1.11 \times 10^{5} \pm$ $2.11 \times 10^{4} \mathrm{~Pa}$. This is in good agreement with the moduli of human tissue. ${ }^{43}$ Therefore, the hydrogel was well suited for the application as bandage. The loss factor was $1.70 \times 10^{-2} \pm 1.48$ $\times 10^{-3}$. A low loss factor is typical for an elastic material.

The average mesh size $\xi$ was calculated using eqn (3). It was 32.3 A. Thus, most photosensitizers (and molecules in general) are much smaller than the meshes of the hydrogel. Therefore, this publication focused on the impact of the properties of the photosensitizers on the transport dynamics.

Additionally, AFM images of the hydrogel were recorded (see Fig. 1). The hydrogel had a smooth and homogeneous surface. Cavities of about 30 to $50 \AA$ were visible. Therefore, the AFM images were in good correlation with the calculated mesh size.

\subsection{Selection and characterization of the photosensitizers}

As mentioned in the introduction (section 1), there is a large variety of photosensitizers. Therefore, for this study a selection was chosen which represents a few main structural motifs of photosensitizers. In Fig. 2 the chosen photosensitizers are 


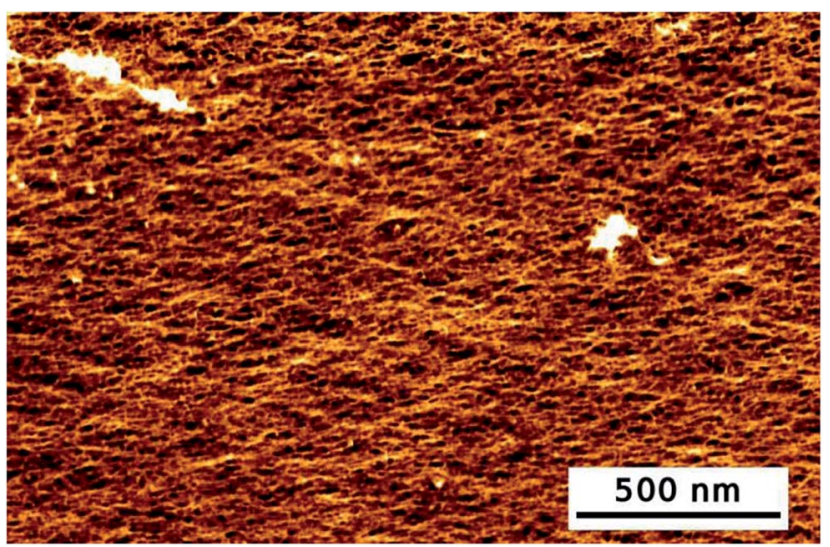

Fig. 1 AFM image of the hydrogel.

displayed. The substances were chosen because all are well known to be excellent photosensitizers. ${ }^{1,10,11,13,17,44}$ Furthermore, they were selected because of their differences in charge, size and absorption wavelength. Two porphyrins (TMPyP and TPPS 4 ) a phenothiazine (methylene blue) and a xanthene (eosin y) have been selected. Each two of them are positively charged and two negative. However, the first $\mathrm{p} K_{\mathrm{a}}$ value of all four photosensitizers was determined to be between $\mathrm{pH} 4$ and 5 (full titration curves were displayed in ESI Fig. 5-8†). Therefore, all are weak acids. The variety of properties should enable to investigate and understand possible influences on the uptake and release behaviour of the hydrogels. An overview of the properties of the chosen photosensitizers is listed in Table 2.

Besides charge and structure, the size could possibly affect the uptake and release behaviour. Therefore, the Stokes radii were determined using eqn (4). Accordingly, the diffusion coefficients were measured using DOSY-NMR. Phosphate buffered $\mathrm{D}_{2} \mathrm{O}$ was used. While the solvent influences the Stokes radii, the values may differ slightly from the radii in water. Nevertheless, the trend is most probably the same in water as in heavy water. The full DOSY spectra are displayed in ESI Fig. 1-4. $\dagger$ TPPS $_{4}$ is the photosensitizer with the largest Stokes radius of $8.9 \AA$ A. There were two photosensitizers with medium Stokes radii, namely TMPyP and eosin $\mathrm{Y}$, which were calculated to be $7.7 \AA$ and $7.1 \AA$ in size, respectively. Methylene blue has the smallest radius of $6.5 \AA$.

Extinction coefficients in water were calculated at the maximal absorption wavelength using eqn (1). The porphyrin photosensitizers had four to six times higher extinction coefficients than the other substances $\left(2.9\right.$ and $2.8 \times 10^{5} 1$ $\mathrm{mol}^{-1} \mathrm{~cm}^{-1}$, respectively for TMPyP and TPPS 4 compared to 7.0 and $6.38 \times 10^{4} \mathrm{l} \mathrm{mol}^{-1} \mathrm{~cm}^{-1}$, respectively for eosin $\mathrm{y}$ and methylene blue). The extinction coefficient is the main property that influences how much a photosensitizer can be immersed and yields a still transparent hydrogel.<smiles>CN(C)c1ccc2nc3ccc(=[N+](C)Cl)cc-3sc2c1</smiles>

Methylene blue (MB)<smiles>N#Cc1ccc(-c2c3nc(c(-c4ccc(S(=O)(=O)[O-])cc4)c4ccc([nH]4)c(-c4ccc(S(=O)(=O)[O-])cc4)c4nc(c(-c5ccc(S(=O)(=O)[O-])cc5)c5ccc2[nH]5)C=C4)C=C3)[nH]1</smiles>

Sodium meso-tetraphenylporphine4,4',4",4'"-tetrasulfonat (TPPS 4 )<smiles>O=C([O-])c1ccccc1-c1c2cc(Br)c(=O)c(Br)c-2oc2c(Br)c(O)c(Br)cc12</smiles>

$\operatorname{Eosin} Y$

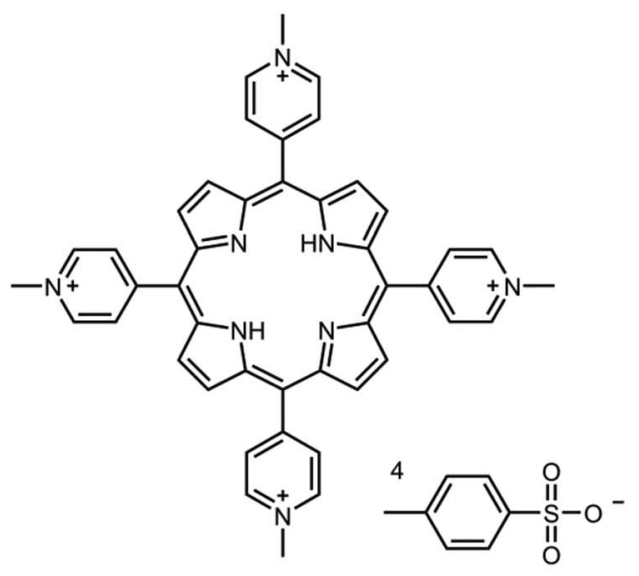

$5,10,15,20-$ Tetrakis(1-methyl-4pyridinio)porphyrin tetra(p-toluenesulfonate) (TMPyP)

Fig. 2 Chemical structures of the investigated photosensitizers: methylene blue (top left), eosin y (top right), sodium meso-tetraphenylporphine-4,4', 4", $4^{\prime \prime \prime}$-tetrasulfonat (bottom left) and 5,10,15,20-tetrakis(1-methyl-4-pyridinio)porphyrin tetra(p-toluene-sulfonate) (bottom right). 
Table 2 Overview of the properties (structure, charge, maximum absorption wavelength, extinction coefficient at maximum wavelength, Stokes radius, and $\mathrm{p} K_{\mathrm{a}}$ in $\mathrm{D}_{2} \mathrm{O}$ ) of the photosensitizers investigated in this study

\begin{tabular}{|c|c|c|c|c|c|c|}
\hline Methylene blue & Phenothiazine & Positive & 665.0 & 6.3 & 6.5 & 4.0 \\
\hline TMPуP & Porphyrin & Positive & 421.0 & 28.2 & 7.7 & 4.8 \\
\hline TPPS $_{4}$ & Porphyrin & Negative & 413.5 & 29.0 & 8.9 & 4.2 \\
\hline
\end{tabular}

High transmittance has to be possessed by the hydrogel to make sure the light can penetrate the hydrogel. Thereby, the photosensitizer can be excited after release to the infected tissue and produce singlet oxygen or other reactive oxygen species. The transmittance of the hydrogel is about $75 \%$ down to a wavelength of $350 \mathrm{~nm}$ (Fig. 3). Therefore, it is an ideal carrier for the photosensitizers investigated here because their absorption maxima were between $413 \mathrm{~nm}$ and $665 \mathrm{~nm}$.

However, expect methylene blue none of the photosensitizers is approved today. Nevertheless, all of them are used in clinical tests or in vivo/in vitro studies. ${ }^{7}$ Furthermore, they are adequate model substances for several other photosensitizers that are approved today.

\subsection{Uptake study}

Uptake of the photosensitizers in the hydrogel is crucial for the envisaged medical application. Furthermore, the dynamics and maximum loading characteristics of the different photosensitizers shall be understood. Thus, the dried hydrogels were immersed in solutions of the photosensitizer with different concentrations. The immersion times were $24 \mathrm{~h}, 48 \mathrm{~h}$ and $120 \mathrm{~h}$, to analyse a time dependency in the uptake behaviour. The concentrations of the immersion solutions were selected regarding the extinction coefficient of the photosensitizers. The higher the extinction coefficients, the lower were the observed concentrations. For methylene blue the immersion concentration was varied between $10^{-2} \mathrm{M}$ and $10^{-4} \mathrm{M}$. Because of the slightly higher excitation, the concentration range for eosin $\mathrm{y}$

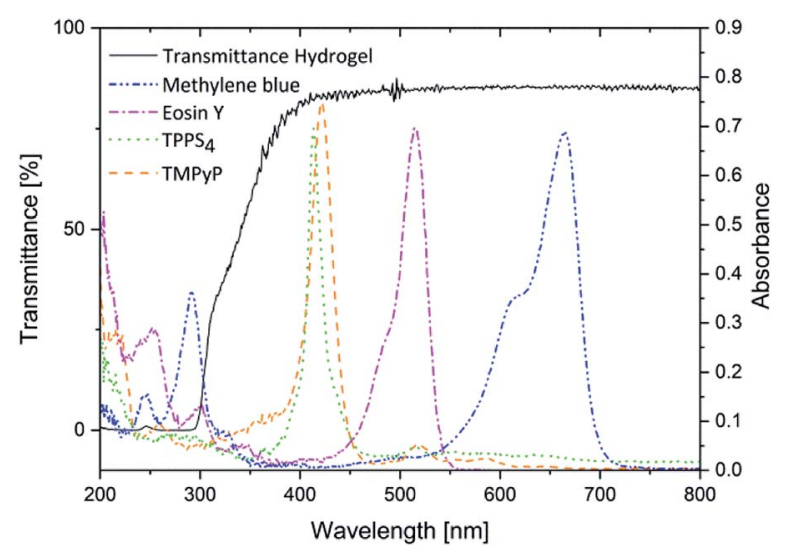

Fig. 3 UV-VIS spectra of the methylene blue (blue dotted line), eosin y (pink dotted line), TMPyP (orange dotted line) and TPPS 4 (green dotted line) compared to the transmittance spectra of the hydrogels (black solid line). was $10^{-2} \mathrm{M}$ and $5 \times 10^{-5} \mathrm{M}$. The extinction coefficients of both porphyrins are nearly one order of magnitude higher. For this reason, the analysed concentrations were chosen to be between $10^{-3} \mathrm{M}$ and $10^{-5} \mathrm{M}$ for TMPyP, and $10^{-3} \mathrm{M}$ and $5 \times 10^{-6} \mathrm{M}$ for $\mathrm{TPPS}_{4}$, respectively. Photos of the gels after immersion are displayed in Fig. 4.

Clearly, all photosensitizer were taken up. Furthermore, the hydrogels were darker coloured when immersed in a solution with a higher concentration. This indicates that more photosensitizer was incorporated in the hydrogels when a larger concentration is offered. Further, there seemed to be no saturation within the observed concentration range.

The transmittance of the dried gels after immersion was determined to support the previous findings. The transmittance spectra of the hydrogel loaded for $48 \mathrm{~h}$ are displayed in Fig. 5 . (In ESI Fig. $9 \dagger$ the transmittance spectra of all hydrogels are presented.) Here, the fact was confirmed that higher immersion concentrations lead to darker coloured hydrogels. Gels immersed in highly concentrated solutions were not even translucent any more. This cut-off concentration was different for every photosensitizer depending on the extinction coefficient. Hydrogels loaded with TPPS $_{4}$ (the photosensitizer with the highest extinction coefficient) were translucent up to a concentration of $5 \times 10^{-6} \mathrm{M}$ and TMPyP loaded gels up to a concentration of $1 \times 10^{-5} \mathrm{M}$. As expected the hydrogels loaded with eosin y and methylene blue were transparent up to higher concentrations ( $5 \times 10^{-5} \mathrm{M}$ and $1 \times 10^{-4} \mathrm{M}$, respectively).

Further, the absolute amounts of the photosensitizers in the hydrogels were determined. Gels with an immersion time of $48 \mathrm{~h}$ were chosen. The gels were diluted in concentrated sodium hydroxide solution. Following, the amount of substance in these solutions was observed using eqn (2). The results are displayed in Fig. 6. Obviously, there is no significant difference within the investigated photosensitizers. This confirmed the results of the former measurements. Additionally, the linear slope indicates that there is no saturation within the observed range of concentrations. This could be quite important for a future application because also high amounts of photosensitizers can be carried within the hydrogels. Finally, the amount of substance in the hydrogels was about 2 times higher than the expected amount. This result can be explained with surface adsorption interactions at the hydrogel.

To enable the kinetic analysis and comparison of the uptake of different photosensitizers, the relative uptake was determined at different times (for the lowest concentration of each photosensitizer). The results are displayed in Fig. 6. No significant differences were found for the uptake of eosin y, TPPS and 

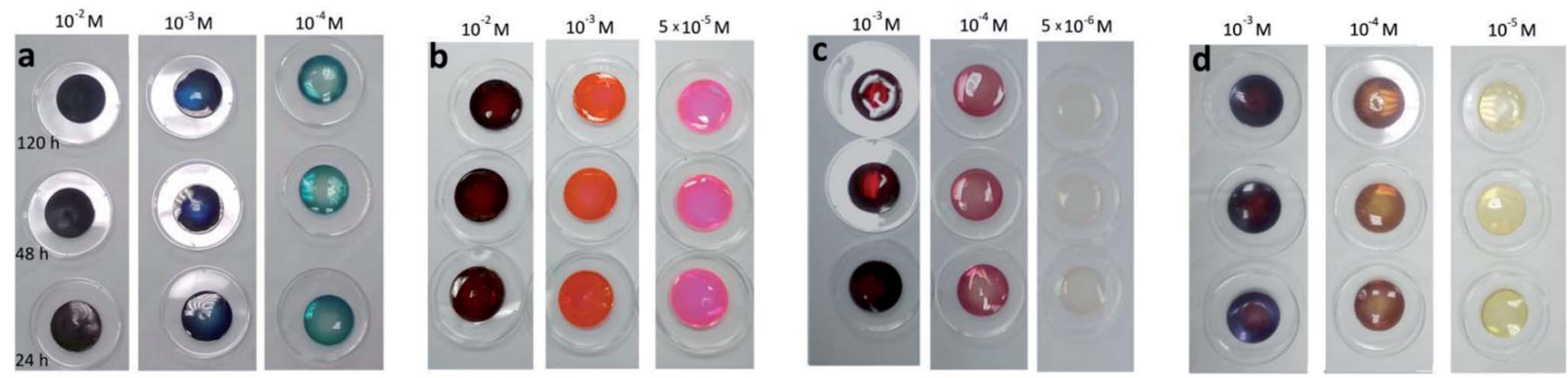

Fig. 4 Photos of the hydrogels immersed in (a) methylene blue $\left(1 \times 10^{-2} \mathrm{M}, 1 \times 10^{-3} \mathrm{M}\right.$ and $\left.1 \times 10^{-4} \mathrm{M}\right)$ (b) eosin y solution (1 $\times 10^{-2} \mathrm{M}, 1 \times$ $10^{-3} \mathrm{M}$ and $\left.5 \times 10^{-5} \mathrm{M}\right)(\mathrm{c}) \mathrm{TPPS}_{4}\left(1 \times 10^{-3} \mathrm{M}, 1 \times 10^{-4} \mathrm{M}\right.$ and $\left.5 \times 10^{-6} \mathrm{M}\right)$ and (d) TMPyP $\left(1 \times 10^{-3} \mathrm{M}, 1 \times 10^{-4} \mathrm{M}\right.$ and $\left.1 \times 10^{-5} \mathrm{M}\right)$ for 24,48 and $120 \mathrm{~h}$. Highest concentration is always on the top, lowest on the bottom.

TMPyP. These compounds reached a plateau after $48 \mathrm{~h}$ with about $250 \%$ amount of substance. However, methylene blue was taken up with $350 \%$ after $48 \mathrm{~h}$ and the uptake amount still increased to $550 \%$ after $120 \mathrm{~h}$ (Fig. 7).

The positively charged methylene blue was taken up to a moderate higher extent compared with the other photosensitizers. This can be explained with the surface charge of PEGDA hydrogels which is almost non-charged $(\sim-1.2 \mathrm{mV}){ }^{45}$ Since the other positively charged photosensitizer TMPyP showed similar uptake characteristics as the two negatively charged compounds, we assume that the charge of the photosensitizers influenced the uptake behaviour of the hydrogels only slightly. Since methylene blue is the smallest and TMPyP is one of the largest investigated photosensitizers ( $6.5 \AA$ iv. $7.7 \AA$ ), this could be one explanation for the uptake differences of both positively charged compounds. However, within the here investigated
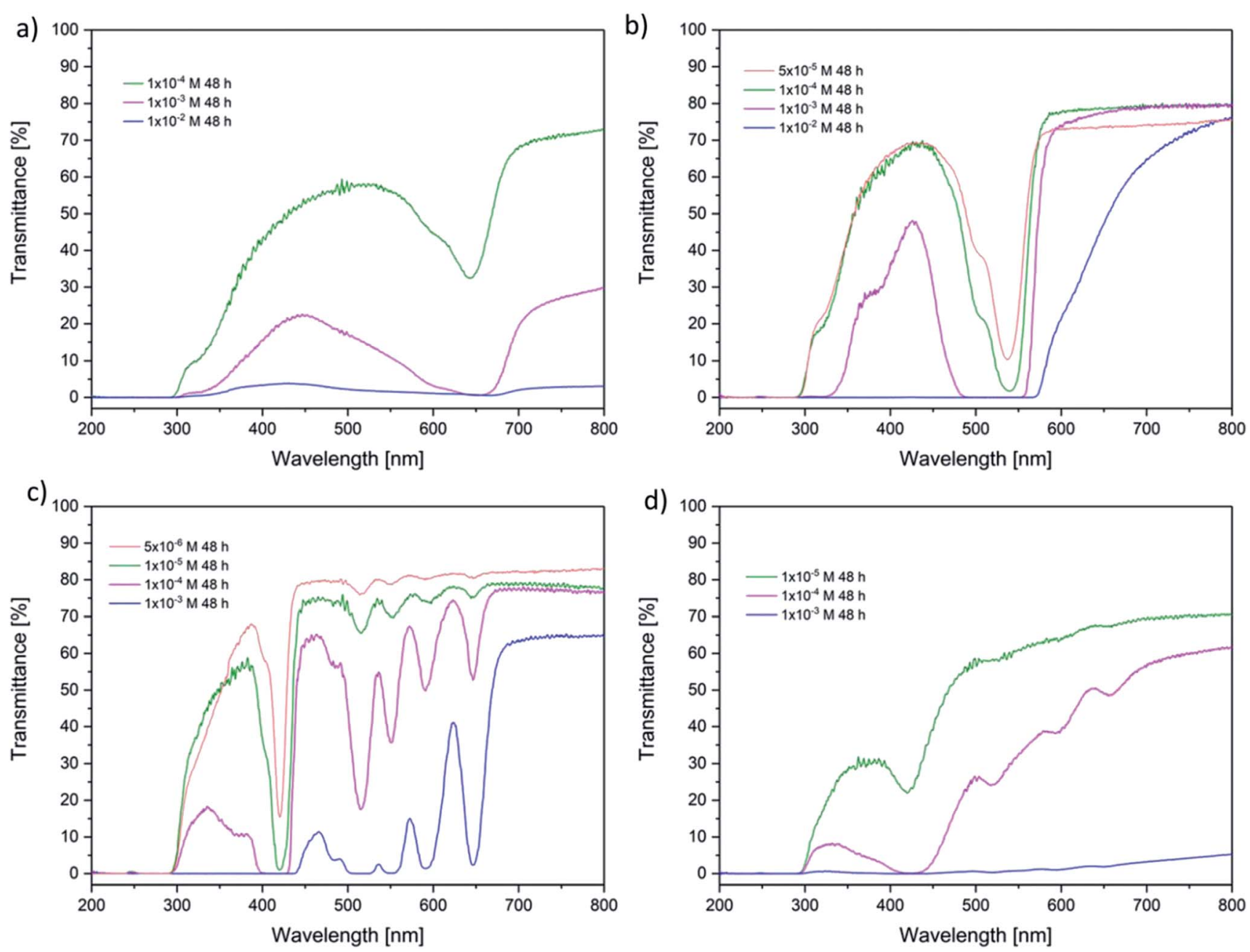

Fig. 5 Transmittance of the hydrogels loaded for $48 \mathrm{~h}$ (a) methylene blue (b) eosin y, (c) TPPS 4 and (d) TMPyP. 


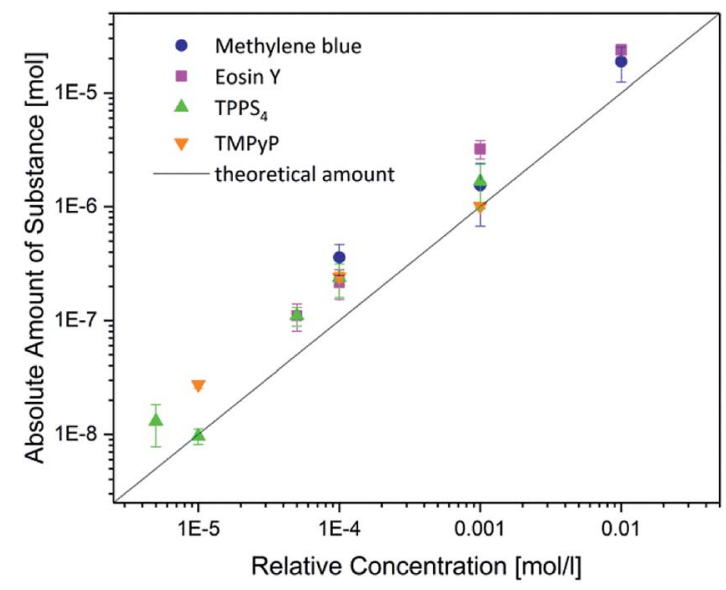

Fig. 6 Absolute uptake of the amount of the photosensitizers in the hydrogels compared to the relative concentration in the immersion solutions.

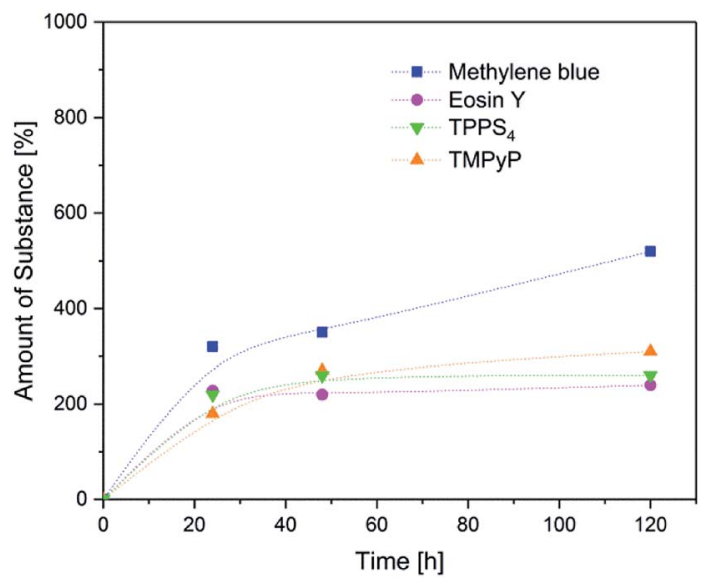

Fig. 7 Relative uptake of the photosensitizers depending on the time. The relative amount of substance was examined for the lowest concentration of photosensitizer $\left(c\left(\right.\right.$ TPPS $\left._{4}\right)=5 \times 10^{-6} \mathrm{M}, c($ TMPyP $)=1$ $\times 10^{-5} \mathrm{M}, c($ eosin $\mathrm{y})=5 \times 10^{-5} \mathrm{M}$ and $c($ methylene blue $\left.)=1 \times 10^{-4} \mathrm{M}\right)$.

range one single property like charge, size or structure seems not to dictate the uptake behaviour.

Additionally, the mechanical properties of the hydrogels were observed before and after loading with the photosensitizers. Neither the moduli nor the loss factor changed (see Table $\mathrm{S} 1 \dagger)$. Therefore, the photosensitizer did not influence the mechanical properties of the hydrogel.

\subsection{Release study}

The photosensitizer release from the hydrogel carrier matrix is crucial for a potential medical treatment, too. Therefore, the loaded gels were placed in PBS buffer in dried state. The PBS buffer was changed frequently, first of all to prevent the formation of equilibrium. The second reason for changing the buffer was to simulate the continuous circulation in the human body.

All release studies were performed using gels immersed in 1 $\times 10^{-4} \mathrm{M}$ photosensitizer solution. The amount of released photosensitizer was compared with the absolute amount of substance in the hydrogel (as shown in Fig. 6). The results are displayed in Fig. 8. Except of $\mathrm{TPPS}_{4}$ all photosensitizers were released to the buffer. In the case of the positively charged methylene blue and TMPyP most of the release took place within the first $8 \mathrm{~h}$ and a maximum plateau was reached after $48 \mathrm{~h}$. The slopes and plateau evolution showed a parallel trend. However, the total amount of released methylene blue (25\%) was about half of the amount of TMPyP (46\%). In the case of the negatively charged eosin y the overall release was the highest (54\%). Furthermore, the released amount didn't reach a plateau within the investigated time range $(72 \mathrm{~h})$. As mentioned before the negatively charged $\mathrm{TPPS}_{4}$ was hardly released at all from the hydrogel.

Obviously, the photosensitizers with the highest $\mathrm{p} K_{\mathrm{a}}$ value showed the best release behaviour in terms of released amount. Additionally, TPPS $_{4}$ which was the largest investigated compound was not released at all. We therefore assume that also the release behaviour is influenced by the interplay of several structural parameters. The size and $\mathrm{p} K_{\mathrm{a}}$ value showed the main impact, while the charge was not affecting the release behaviour noteworthy.

\subsection{Singlet oxygen generation}

Finally, singlet oxygen generation of methylene blue after release was investigated (representative for all photosensitizer compounds). For this purpose, the fluorescent substance $\mathrm{ABDA}^{\mathbf{4 6}}$ was monitored. ABDA is sensitive to singlet oxygen and loses its fluorescence $(422 \mathrm{~nm})$ due to oxidation by singlet oxygen.

The amount of ABDA was about 10 times higher than the amount of photosensitizer in this test $\left(3 \times 10^{-6} \mathrm{M}\right.$ compared to $\left.3.6 \times 10^{-7} \mathrm{M}\right)$. The results of the degradation of ABDA are displayed in Fig. 9. ABDA was completely degraded after $90 \mathrm{~min}$. That means methylene blue is still active and produces a high amount of singlet oxygen. The degradation was slower within the first $30 \mathrm{~min}$ (about 25\% degradation) because the photosensitizer was released slowly to the surrounding liquid. Afterwards, the singlet oxygen production was much faster and $95 \%$

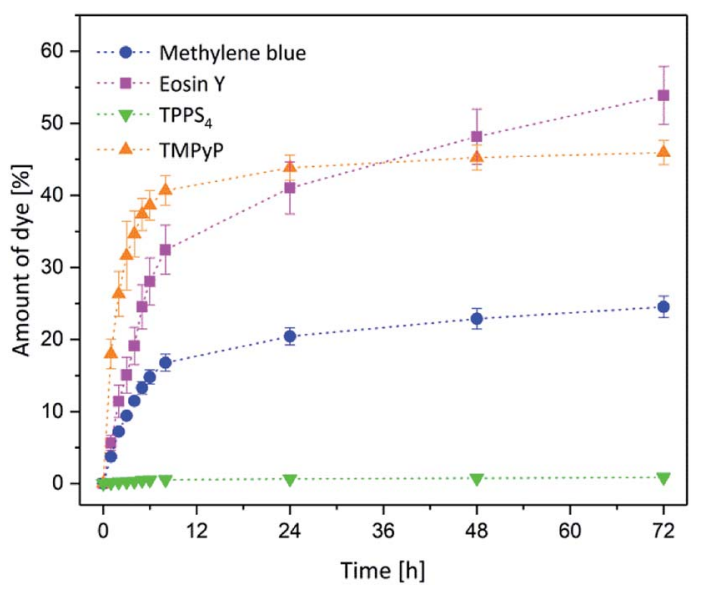

Fig. 8 Release of methylene blue (blue dot), eosin y (pink square), TMPyP (orange bottom-up triangle) and $\mathrm{TPPS}_{4}$ (green triangle). 


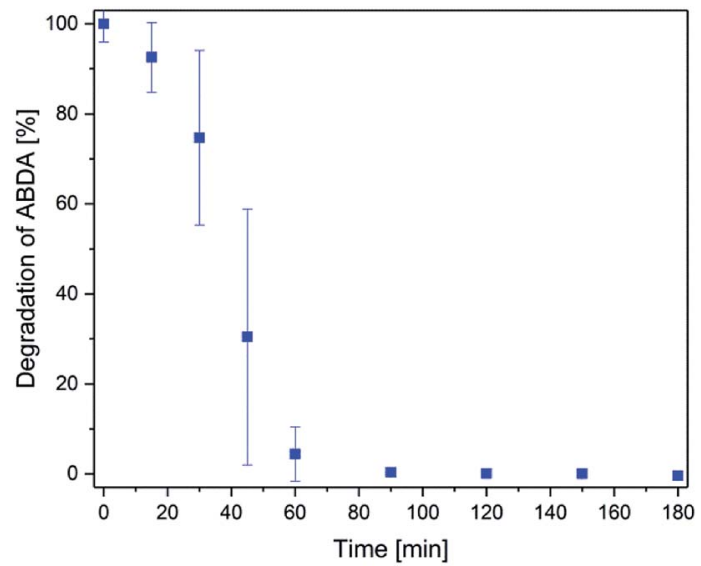

Fig. 9 Degradation of ABDA by singlet oxygen produced by the methylene blue released from a hydrogel with time.

ABDA was degraded within $60 \mathrm{~min}$. In conclusion, methylene blue is still highly effective after the release from the hydrogel. This is a very important aspect regarding the future medical application.

\section{Conclusions}

This study demonstrated that transparent hydrogels could be ideal carriers for photosensitizers in medical application such as photodynamic therapy. The PEGDA hydrogel used here can be used for different photosensitizers with varying structural properties. All substances were taken up comparably. Neither size, charge nor the chemical structure had a major effect on the uptake behaviour. Additionally, it was possible to implement even high amounts $\left(10^{-2} \mathrm{M}\right)$ of photosensitizers. Depending on the photosensitizer concentration the transmittance changed. To keep the hydrogels translucent low amounts of photosensitizers can be used. The transmittance of the photosensitizer in the hydrogel is mainly depending on the extinction coefficient of the photosensitizer.

Furthermore, the release behaviour of the photosensitizers from the hydrogels was studied. The release behaviour was influenced by size and $\mathrm{p} K_{\mathrm{a}}$ mainly. Because of the interplay of these properties no distinct trend was observed for the different investigated compounds. Therefore, it will be necessary to consider the release behaviour for every additional photosensitizer independently. Understanding the influencing structural properties, an individualized medical treatment regarding release time (=treatment time) and/or photosensitizer concentration (=singlet oxygen generation) is possible. Therefore, further approved photosensitizers shall be observed in the future.

Finally, the singlet oxygen generation of the photosensitizer (one representative case) was demonstrated after release from the hydrogel by degradation of ABDA. The fluorescent test molecule was degraded within $60 \mathrm{~min}$. This confirmed the high activity of the photosensitizer after release. Consequently, hydrogels and in particular the hydrogel employed in this study are well suited to support a broad variation of photosensitizers applied in photodynamic therapy.

\section{Conflicts of interest}

There are no conflicts to declare.

\section{Acknowledgements}

S. Glass is grateful for support within the IOM Research Group "Schalten mit Licht". B. Abel thanks the Miller Insitute (UC Berkeley) for a Somorjai-Miller-Guest-Professorship Award. The authors are thankful to the Fraunhofer Institute for Microstructure of Materials and Systems (IMWS) and Matthias Menzel for recording the AFM images. Additionally, the authors thank Andrea Prager for preparing the cryocut of the hydrogel.

\section{References}

1 D. E. J. G. J. Dolmans, D. Fukumura and R. K. Jain, Nat. Rev. Cancer, 2003, 3, 380-387.

2 O. Raab, Z. Biol., 1900, 39, 524-546.

3 F. H. J. Figge, G. S. Weiland and L. O. J. Manganiello, Proc. Soc. Exp. Biol. Med., 1948, 68, 640-641.

4 A. Juzeniene, Q. Peng and J. Moan, Photochem. Photobiol. Sci., 2007, 6, 1234-1245.

5 J. Bogdan, J. Pławińska-Czarnak and J. Zarzyńska, Nanoscale Res. Lett., 2017, 12, 225.

6 S. Glass, B. Trinklein, B. Abel and A. Schulze, Front. Chem., 2018, 6, 340 .

7 A. B. F. Ormond and H. S., Materials, 2013, 6, 817-840.

8 K. Ergaieg, M. Chevanne, J. Cillard and R. Seux, Sol. Energy, 2008, 82, 1107-1117.

9 M. P. Cormick, E. D. Quiroga, S. G. Bertolotti, M. G. Alvarez and E. N. Durantini, Photochem. Photobiol. Sci., 2011, 10, 1556-1561.

10 A. Preuss, L. Zeugner, S. Hackbarth, M. A. Faustino, M. G. Neves, J. A. Cavaleiro and B. Roeder, J. Appl. Microbiol., 2013, 114, 36-43.

11 K. Berg, P. K. Selbo, A. Weyergang, A. Dietze, L. Prasmickaite, A. Bonsted, B. Ø. Engesaeter, E. Angell-Petersen, T. Warloe, N. Frandsen and A. HøGset, J. Microsc., 2005, 218, 133-147. 12 K. Konopka and T. Goslinski, J. Dent. Res., 2007, 86, 694-707. 13 T. Maisch, F. Spannberger, J. Regensburger, A. Felgenträger and W. Bäumler, J. Ind. Microbiol. Biotechnol., 2012, 39, 1013-1021.

14 L. Xu, N. Sheybani, W. A. Yeudall and H. Yang, Biomater. Sci., 2015, 3, 250-255.

15 G. A. Johnson, N. Muthukrishnan and J.-P. Pellois, Bioconjugate Chem., 2013, 24, 114-123.

16 G. A. Johnson, E. A. Ellis, H. Kim, N. Muthukrishnan, T. Snavely and J.-P. Pellois, PLoS One, 2014, 9, e91220.

17 J. P. Tardivo, A. Del Giglio, C. S. de Oliveira, D. S. Gabrielli, H. C. Junqueira, D. B. Tada, D. Severino, R. de Fátima Turchiello and M. S. Baptista, Photodiagn. Photodyn. Ther., 2005, 2, 175-191.

18 S. Menezes, M. A. M. Capella and L. R. Caldas, J. Photochem. Photobiol., B, 1990, 5, 505-517.

19 M. Tanaka, M. Kinoshita, Y. Yoshihara, N. Shinomiya, S. Seki, K. Nemoto, T. Hirayama, T. Dai, L. Huang, 
M. R. Hamblin and Y. Morimoto, Photochem. Photobiol., 2012, 88, 227-232.

20 V. Nesi-Reis, D. S. S. L. Lera-Nonose, J. Oyama, M. P. P. SilvaLalucci, I. G. Demarchi, S. M. A. Aristides, J. J. V. Teixeira, T. G. V. Silveira and M. V. C. Lonardoni, Photodiagn. Photodyn. Ther., 2018, 21, 294-305.

21 A. Bennewitz, M. Prinz and U. Wollina, Kosmetische Medizin, 2013, 34, 208-215.

22 N. Lohmann, L. Schirmer, P. Atallah, E. Wandel, R. A. Ferrer, C. Werner, J. C. Simon, S. Franz and U. Freudenberg, Sci. Transl. Med., 2017, 9, eaai9044.

23 Q. Chai, Y. Jiao and X. Yu, Gels, 2017, 3, 6.

24 A. T. Debele, S. Peng and H.-C. Tsai, Int. J. Mol. Sci., 2015, 16, 22094-22136.

25 A. Bullock, P. Pickavance, D. Haddow, S. Rimmer and S. MacNeil, Regener. Med., 2010, 5, 55-64.

26 Haryanto, S. Kim, J. H. Kim, J. O. Kim, S. Ku, H. Cho, D. H. Han and P. Huh, Macromol. Res., 2014, 22, 131-138.

27 E. M. Ahmed, J. Adv. Res., 2015, 6, 105-121.

28 X. S. Wu, A. S. Hoffman and P. Yager, J. Polym. Sci., Part A: Polym. Chem., 1992, 30, 2121-2129.

29 E. W. Merrill, K. A. Dennison and C. Sung, Biomaterials, 1993, 14, 1117-1126.

30 L. Yean, C. Bunel and J.-P. Vairon, Makromol. Chem., 1990, 191, 1119-1129.

31 N. C. Padmavathi and P. R. Chatterji, Macromolecules, 1996, 29, 1976-1979.

32 H. Jiang, W. Su, P. T. Mather and T. J. Bunning, Polymer, 1999, 40, 4593-4602.
33 E. I. Wisotzki, M. Hennes, C. Schuldt, F. Engert, W. Knolle, U. Decker, J. A. Käs, M. Zink and S. G. Mayr, J. Mater. Chem. B, 2014, 2, 4297-4309.

34 A. C. Jen, M. C. Wake and A. G. Mikos, Biotechnol. Bioeng., 1996, 50, 357-364.

35 K. Y. Lee and D. J. Mooney, Chem. Rev., 2001, 101, 1869-1879.

36 T. R. Hoare and D. S. Kohane, Polymer, 2008, 49, 1993-2007.

37 J. Dissemond, M. Augustin, S. A. Eming, T. Goerge, T. Horn,

S. Karrer, H. Schumann and M. Stücker, Journal der Deutschen Dermatologischen Gesellschaft, 2014, 12, 541-554.

38 T. Pelras, S. Glass, T. Scherzer, C. Elsner, A. Schulze and B. Abel, Polymers, 2017, 9, 639.

39 A. Beer, Ann. Phys. Chem., 1852, 86, 78-88.

40 A. Hajighasem and K. Kabiri, J. Polym. Res., 2013, 20, 218.

41 Y. Tsuji, X. Li and M. Shibayama, Gels, 2018, 4, 50.

42 R. C. Hardy and R. L. Cottington, J. Chem. Phys., 1949, 17, 509-512.

43 X. Liang and S. A. Boppart, IEEE Trans. Biomed. Eng., 2010, 57, 953-959.

44 K. Tamai, T. Mizushima, X. Wu, A. Inoue, M. Ota, Y. Yokoyama, N. Miyoshi, N. Haraguchi, H. Takahashi, J. Nishimura, T. Hata, C. Matsuda, Y. Doki, M. Mori and H. Yamamoto, Mol. Cancer Ther., 2018, 1613-1622.

45 T. Fei, X. Xiaoding, D. Ting, Y. Miao, Z. Xianzheng and W. Jiawei, Biomed. Mater., 2012, 7, 055009.

46 A. Gomes, E. Fernandes and J. L. F. C. Lima, J. Biochem. Biophys. Methods, 2005, 65, 45-80.

47 H. Kautsky and H. de Bruijn, Naturwissenschaften, 1931, 19, 1043-1043. 